\title{
Características patogênicas de isolados do complexo Fusarium graminearum e de Fusarium verticillioides em sementes e plântulas de milho
}

\author{
Pathogenic traits of Fusarium graminearum complex and Fusarium verticillioides isolates on seeds \\ and seedlings of maize
}

\author{
Paulo Roberto Kuhnem Júnior ${ }^{I}$ Raquel Stumpf ${ }^{1}$ Pierri Spolti $^{I}$ Emerson Medeiros Del Ponte $^{\mathrm{I}}$
}

RESUMO

No Brasil, diversas espécies de Fusarium são patogênicas ao milho, afetando sementes, plântulas, colmos $e$ grãos. Objetivou-se comparar isolados de $\boldsymbol{F}$. verticillioides e de duas espécies do complexo $\boldsymbol{F}$. graminearum (F. graminearum sensu stricto e $\boldsymbol{F}$. meridionale), de ocorrência predominante em sementes de milho, quanto à taxa de crescimento micelial, capacidade de colonização e redução da germinação da semente, redução da emergência de plântulas e infecção e colonização de colmos de milho.Testes permutacionais e análise de contrasteforam usados para discriminar os isolados. Análise de componentes principais foi utilizada para identificar as variáveis responsáveis pela maior variância entre os isolados. Com exceção da redução da germinação, os isolados $\boldsymbol{F}$. verticillioides apresentaram menores valores de taxa de crescimento micelial, eficiência de infecção, redução na emergência de plântulas e comprimento de lesão em colmos, quando comparados aos demais, que não se diferenciaram. As variáveis redução da emergência e redução da germinação apresentaram maior influência na caracterização dos isolados, sugerindo que sementes infectadas com isolados de qualquer uma das espécies do complexo $\boldsymbol{F}$. graminearum testadas representam maior risco ao estabelecimento da cultura do que isolados de $\boldsymbol{F}$. verticillioides.

Palavras-chave: Gibberella zeae, Gibberela fujikuroi, Zea mays L., podridão do colmo.

\section{ABSTRACT}

In Brazil, several Fusarium species are pathogenic to corn affecting seeds, seedlings, stalks and grains. This research aimed to compare isolates from $\boldsymbol{F}$. verticillioides and from two species of the $\boldsymbol{F}$. graminearum complex (F. graminearum sensu stricto and $\boldsymbol{F}$. meridionale) prevalent on corn seeds in relation to mycelial growth rate, ability to colonize and reduce seed germination, reduction in seedling emergence and infection and colonization of corn stalk. Permutational test and contrast analysis was performed to discriminate the isolates and species. Principal component analysis was used to identify the variables leading to greatest variance among the isolates. With the exception of seed germination, $\boldsymbol{F}$. verticillioides isolates showed lower values for mycelial growth rate, infection efficiency, reduction in seedling emergence and lesion size than $\boldsymbol{F}$. graminearum complex isolates that were all similar. Seedling emergence and seed germination showed greater influence on the characterization of isolates, suggesting that seeds infected with $\boldsymbol{F}$. graminearum isolates of any of the species tested represent a greater threat to crop stand than $\boldsymbol{F}$. verticillioides isolates.

Key words: Gibberella zeae, Gibberela fujikuroi, Zea mays $L$., stalk rots.

\section{INTRODUÇÃO}

Os fitopatógenos Fusarium verticillioides e $\boldsymbol{F}$. graminearum estão entre os mais importantes na cultura do milho, causando doenças diversas como podridão radicular, morte de plântulas, podridão de espiga, podridão de colmo, podendo levar a reduções na produtividade e qualidade de grãos em todo o mundo (MUNKVOLD, 2003). Ambas as espécies são capazes de produzir micotoxinas, sendo que as fumonisinas são mais comumente associadas $\operatorname{com} \boldsymbol{F}$. verticillioides e desoxinivalenol (DON) e nivalenol (NIV), do grupo tricoteceno do tipo B, com $\boldsymbol{F}$. graminearum (MUNKVOLD \& DESJARDINS, 1997). Estudos filogenéticos determinaram que $\boldsymbol{F}$. graminearum constitui um complexo com pelo

'Departamento de Fitossanidade, Faculdade de Agronomia, Universidade Federal do Rio Grande do Sul (UFRGS), 90001-970, Porto Alegre, RS, Brasil. E-mail: emerson.delponte@ ufrgs.br. *Autor para correspondência. 
menos 15 espécies (SARVER et al., 2011). Isolados do complexo $\boldsymbol{F}$. graminearum (Fg) variam quanto ao fenótipo químico (quimiotipo) em relação aos tricoteceno-B. Métodos moleculares têm sido usados para genotipar isolados, pela presença de alelos de genes relacionados à síntese dessas micotoxinas (DESJARDINS, 2008).

Estudos populacionais do complexo Fg no Brasil mostraram a ocorrência de múltiplas espécies desse complexo associadas com trigo e cevada, com consistência entre a espécie e o genótipo tricoteceno: $\boldsymbol{F}$. meridionale apresenta o genótipo NIV e F. graminearum sensu stricto (s.s.) o genótipo 15ADON, sendo este último a espécie predominante nos dois cereais de inverno (>80\%) (ASTOLFI et al., 2012; 2011). Enquanto $\boldsymbol{F}$. graminearum é relatado na Ásia, Europa e nas Américas como patogênico a diversos cereais, causando principalmente a giberela na espiga e a podridão radicular, Fusarium verticillioides é relatado ao redor do mundo como patogênico somente ao milho (MUNKVOLD, 2003; JURJEVIC et al., 2005; NDOYE et al., 2012). No Brasil, $\boldsymbol{F}$. verticillioides é de ocorrência comum e frequente em sementes e grãos de milho produzido em todas as regiões do Brasil (RIBEIRO et al., 2005; NERBASS et al., 2008). Já $\boldsymbol{F}$. graminearum é mais frequente em milho no sul do Brasil, quando comparado à região central do país, possivelmente pela maior quantidade de inóculo, uma vez que no sul é comum a sucessão trigo-milho (STUMPF et al., 2013; CASA et al., 1998). Dois estudos de levantamento de espécies e genótipos toxigênicos do complexo $F g$, por métodos moleculares, em grãos do Estado do Rio Grande do Sul (STUMPF et al., 2013) e do Brasil Central (SILVA, 2011), foi observado um predomínio de $\boldsymbol{F}$. meridionale em relação à $\boldsymbol{F}$. graminearum s.s. com os mesmos genótipos tricoteceno ocorrentes em trigo.

É sabido que Fusarium verticillioides tem a capacidade de transmitir-se para as espigas de forma sistêmica a partir de sementes (WILKE et al., 2007). No entanto, pouco se conhece sobre o efeito diferencial das espécies do complexo $F g$ patogênicas ao milho na introdução, no estabelecimento e na transmissão para a parte aérea, bem como se há diferenças fenotípicas que determinam vantagem adaptativa ou de competitividade entre as espécies ou genótipos tricotecenos distintos. Considerando que há no Brasil diversidade de espécies e genótipos toxigênicos de Fusarium que ocorrem em milho, o objetivo do estudo foi comparar a patogenicidade e agressividade de uma coleção de isolados de $\boldsymbol{F}$. verticillioides e de duas espécies do complexo $\boldsymbol{F}$. graminearum obtidos de grãos de milho.

\section{MATERIAL E MÉTODOS}

\section{Coleção de isolados}

A partir de um estudo prévio de levantamento de Fusarium spp. em grãos de milho no estado do Rio Grande do Sul, foram selecionados seis $\boldsymbol{F}$. verticillioides positivos para o gene FUM-1 e seis do complexo Fg, sendo quatro $\boldsymbol{F}$. meridionale com genótipo NIV e dois $\boldsymbol{F}$. graminearum s.s., com genótipo 15-ADON, determinados por métodos moleculares (STUMPF et al., 2013).

\section{Caracterização fenotípica e de agressividade}

Taxa de crescimento micelial (TCM) Colônias fúngicas dos isolados oriundos da coleção foram cultivadas em meio BDA por sete dias para a retirada de discos de micélio com seis $\mathrm{mm}$ de diâmetros, os quais foram transferidos para o centro de novas placas contendo BDA. Essas foram mantidas a $25 \pm 2{ }^{\circ} \mathrm{C}$ em escuro contínuo. O diâmetro da colônia foi medido a cada $24 \mathrm{~h}$, por cinco dias, em duas direções perpendiculares. Foram utilizadas cinco repetições por isolado. A média do diâmetro da colônia foi utilizada para calcular a taxa de crescimento micelial de cada isolado (SPOLTI et al., 2012).

Semente totalmente colonizada (STC) e redução da germinação das sementes (RE_GER) Foram usadas sementes não tratadas do híbrido 30F53 (Pioneer), as quais foram inoculadas sob condições de restrição hídrica em substrato BDA (MACHADO et al., 2001). O meio de cultura foi ajustado para o potencial osmótico de $-1,2 \mathrm{MPa}$, com adição de $\mathrm{NaCl}\left(9,3 \mathrm{gL}^{-1}\right)$. Uma suspensão de esporos $\left(10^{2}\right.$ conídiosmL $\left.{ }^{-1}\right)$ de cada isolado foi distribuída sobre placas contendo meio de BDA, as quais foram incubadas por cinco dias a $25 \pm 2{ }^{\circ} \mathrm{C}$. Após, foram distribuídas 25 sementes de milho por placa. Novamente, as placas foram levadas para a câmara de crescimento, onde permaneceram por $120 \mathrm{~h}$. Ao fim desse período, as sementes foram secas em fluxo laminar por $24 \mathrm{~h}$ e desinfestadas superficialmente com álcool (95\%) e hipoclorito de sódio 1\% (1min). Para cada isolado, foram plaqueadas 200 sementes em gerbox $\left(25\right.$ sementesgerbox $\left.^{-1}\right)$ acondicionados em fotoperíodo de $12 \mathrm{~h} \mathrm{a} 25^{\circ} \mathrm{C}$. Nessas sementes, avaliouse a incidência (\%) de sementes colonizadas após 48 , 96 e 144h e o poder germinativo após sete dias de incubação. Foram consideradas germinadas aquelas com desenvolvimento das estruturas essenciais do embrião (raízes e mesocótilo), demonstrando sua aptidão para produzir uma planta (RAS, 2009).

Redução da emergência de plântulas (RE_ EMER) - Em copos plásticos de 0,3L (altura de $8,5 \mathrm{~cm}$ e diâmetro de $7 \mathrm{~cm}$ ), contendo substrato de húmus 
esterilizado, foram semeadas sementes previamente inoculadas com os isolados avaliados, sob condições de restrição hídrica, conforme descrito anteriormente. Em cada copo, foram semeadas duas sementes a uma profundidade de $1,5 \mathrm{~cm}$ cada. Após a semeadura, distribuíram-se ao acaso os copos em câmara de crescimento a $23^{\circ} \mathrm{C}$ e fotoperíodo alternado de $12 \mathrm{~h}$ de luz branca fluorescente por 10 dias. Foram avaliados 13 tratamentos, sendo 12 isolados e uma testemunha não inoculada com o patógeno.

Comprimento de lesões em colmos (CL) A caracterização da agressividade dos isolados foi avaliada pela inoculação em colmos de plântulas de milho (DAMICONE et al., 1988). Sementes previamente desinfestadas superficialmente com hipoclorito de sódio (1\%) por 1 minuto, seguido de duas lavagens com água esterilizada e por termoterapia com imersão das sementes em água aquecida a $60^{\circ} \mathrm{C}$ por 5 minutos foram semeadas em substrato de húmus em vasos de 3L. Após a semeadura, os vasos foram mantidos em casa de vegetação com ambiente controlado, com temperatura de aproximadamente $25^{\circ} \mathrm{C}$ e umidade relativa do ar de $80 \%$, até o momento da avaliação. Vinte dias após o semeio, as plântulas foram inoculadas em um único ponto do colmo, cerca de $1 \mathrm{~cm}$ acima do substrato, utilizando-se palitos de dente esterilizados em contato prévio com a colônia fúngica pela raspagem superficial do micélio, os quais foram mantidos no local da inoculação por $48 \mathrm{~h}$. Dez dias após a inoculação, as plântulas foram avaliadas quanto à presença de sintoma no interior do colmo pelo corte transversal. Quando presente, a lesão foi mensurada considerando a área doente com sintoma de descoloração dos tecidos.

Delineamento experimental e análises estatísticas Para todos os ensaios, foi utilizado o delineamento experimental inteiramente casualizado, com cinco repetições por tratamento. Cada isolado foi considerado um tratamento, perfazendo 13 tratamentos quando da inclusão de uma testemunha, no caso do ensaio de inoculação em colmos. Para todas as variáveis, foi realizado teste de permutação para avaliar a significância da variância entre os isolados a partir de uma matriz de semelhança entre as unidades amostrais, estabelecida pela distância Euclidiana (TORRES et al., 2010). As médias das variáveis independentes foram discriminadas por pareamento e, quando significativas, foi realizado contraste ortogonal entre isolados de espécies dos diferentes complexos ( $\boldsymbol{F}$. verticillioides vs. Fg), entre isolados das duas espécies do complexo $\mathrm{Fg}$ (F. graminearum s.s. vs. $\boldsymbol{F}$. meridionale) e entre $\boldsymbol{F}$. verticillioides e as duas do complexo $\mathrm{Fg}(\boldsymbol{F}$. verticillioides vs. $F$. meridionale; $\boldsymbol{F}$. verticillioides vs. F. graminearum s.s.). A significância do contraste foi definida com 10.000 permutações (TORRES et al., 2010). Para identificar quais variáveis apresentam maior influência na caracterização dos isolados, foi realizada análise de componentes principais. Assim, foram extraídos os fatores com autovalores $\geq 1$, considerando também a contribuição da variância total acumulada nos componentes principais sequenciais $\geq 70 \%$. A significância dos eixos selecionados foi avaliada pela auto reamostragem (1.000 permutações), em que, para: $\mathrm{P}(\theta \mathrm{i} \geq \theta \mathrm{i}) \leq \alpha$, rejeita-se a hipótese nula e se assume a estruturação significativa dos eixos (PILLAR, 1999), sendo que, no presente trabalho, não foi adotado um limiar para $\alpha$, buscando evitar o erro do Tipo II, dado o pequeno número de unidades amostrais para cada variável $(n=84)$. Todas as análises estatísticas multivariadas foram realizadas com auxílio do programa MULTIV versão 2.4.2 (PILLAR, 2001).

\section{RESULTADO E DISCUSSÃO}

Para todas as variáveis analisadas, foi observada evidência do efeito do isolado $(\mathrm{P} \leq 0.0004)$ (Tabela 1). A taxa de crescimento micelial variou de $2,39 \mathrm{~mm}$ $\mathrm{dia}^{-1}$ a $5,18 \mathrm{~mm} \mathrm{dia}^{-1}$. Isolados do complexo $\mathrm{Fg}$ apresentaram uma maior taxa média $\left(4,57 \mathrm{~mm} \mathrm{dia}^{-1}\right)$ do que os isolados $\boldsymbol{F}$. verticillioides $\left(2,73 \mathrm{~mm} \mathrm{dia}^{-1}\right)$ $(\mathrm{P}=0,0008)$. Não foi observada diferença na média do crescimento micelial entre as espécies do complexo Fg (Tabela 1), contrariando estudos com dois isolados de F. graminearum s.s. e dois $\boldsymbol{F}$. meridionale, oriundos de trigo e cevada, em que os autores observaram que a taxa de crescimento micelial média de $\boldsymbol{F}$. graminearum s.s. $\left(7,9 \mathrm{~mm} \mathrm{dia}^{-1}\right)$ foi maior do que isolados $\boldsymbol{F}$. meridionale $\left(5,9 \mathrm{~mm} \mathrm{dia}^{-1}\right)$ (SPOLTI et al., 2012). Essas diferenças podem ser devidas à variação entre indivíduos, sendo que um isolado $\boldsymbol{F}$. meridionale do presente estudo apresentou uma taxa similar aos dois isolados $\boldsymbol{F}$. meridionale no estudo de SPOLTI et al. (2012). Em um estudo com inoculação artificial de Fusarium spp. em espigas de milho, foi observado que o crescimento de $\boldsymbol{F}$. graminearum foi superior ao de $\boldsymbol{F}$. verticillioides, quando inoculado isoladamente, e que, em inoculações com mistura dessas espécies, a taxa de crescimento de $\boldsymbol{F}$. graminearum foi baixa, indicando alguma interferência de $\boldsymbol{F}$. verticillioides (STEWART et al., 2002). Apenas em dois dos seis isolados de $\boldsymbol{F}$. verticillioides, foi possível observar sementes totalmente colonizadas pelo fungo após $48 \mathrm{~h}$ da inoculação, com incidência média de 1,5\% (Tabela 1). Já para os isolados do complexo Fg a incidência no mesmo período variou de $12 \%$ a $91 \%$, com média 
Tabela 1 -Análise de variância por testes de permutação para crescimento micelial e características de patogenicidade para seis isolados Fusarium verticillioides (Fvert) e seis isolados do complexo Fusarium graminearum (Fg), sendo quatro $\boldsymbol{F}$. meridionale (Fmer) e dois $\boldsymbol{F}$. graminearum sensu stricto (Fgss).

\begin{tabular}{|c|c|c|c|c|c|}
\hline Isolado & $\mathrm{TCM}^{1}(\mathrm{~mm} / \mathrm{dia})$ & STC $48 h^{2}(\%)$ & RE_GER ${ }^{3}(\%)$ & RE_EMER ${ }^{4}(\%)$ & $\mathrm{CL}^{5}(\mathrm{~cm})$ \\
\hline Fvert & 2,39 & 0,00 & 50,00 & 54,55 & 0,90 \\
\hline Fvert & 2,66 & 8,00 & 86,96 & 72,73 & 1,08 \\
\hline Fvert & 2,74 & 0,00 & 70,65 & 68,18 & 1,25 \\
\hline Fvert & 2,81 & 0,00 & 61,96 & 68,18 & 1,08 \\
\hline Fvert & 2,75 & 1,00 & 64,13 & 50,00 & 0,85 \\
\hline Fvert & 3,02 & 0,00 & 83,70 & 77,27 & 1,10 \\
\hline \multicolumn{6}{|l|}{$\mathrm{Fg}$} \\
\hline Fmer & 4,81 & 90,00 & 80,43 & 88,64 & 2,70 \\
\hline Fmer & 4,65 & 43,00 & 60,87 & 95,45 & 3,50 \\
\hline Fmer & 5,02 & 12,00 & 89,13 & 54,55 & 0,63 \\
\hline Fmer & 2,89 & 91,00 & 93,48 & 100,00 & 2,50 \\
\hline Fgss & 5,18 & 51,00 & 66,30 & 81,82 & 1,10 \\
\hline Fgss & 4,86 & 24,00 & 84,78 & 100,00 & 5,35 \\
\hline Média Fvert & 2,73 & 1,50 & 69,57 & 65,15 & 1,04 \\
\hline Média Fg & 4,57 & 51,83 & 79,17 & 86,74 & 2,63 \\
\hline Média Fmer & 4,34 & 59,00 & 80,98 & 86,66 & 2,33 \\
\hline Média Fgss & 5,02 & 37,50 & 75,54 & 90,91 & 3,23 \\
\hline Valor de $\mathrm{P}$ & 0,0004 & 0,0001 & 0,0001 & 0,0001 & 0,0001 \\
\hline Contrastes & - & ------------------ & ficância (valor de $\mathrm{F}$ & 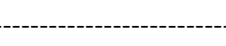 & - \\
\hline Fvert vs Fg & 0,0008 & 0,0001 & 0,0449 & 0,0011 & 0,0001 \\
\hline Fmer vs Fgss & 0,4483 & 0,3461 & 0,4874 & 0,4398 & 0,4403 \\
\hline Fvert vs Fmer & 0,0099 & 0,0001 & 0,0429 & 0,0098 & 0,0004 \\
\hline Fvert vs Fgss & 0,0023 & 0,0001 & 0,3446 & 0,0016 & 0,0002 \\
\hline Síntese & $\mathrm{Fv}<$ Fmer $=$ Fgss & $\mathrm{Fv}<$ Fmer $=$ Fgss & $\mathrm{Fv}=\mathrm{Fgss}<\mathrm{Fmer}$ & $\mathrm{Fv}<$ Fmer $=$ Fgss & $\mathrm{Fv}<$ Fmer $=$ Fgss \\
\hline
\end{tabular}

${ }^{1}$ Taxa de crescimento micelial.

${ }^{2}$ Semente totalmente colonizada após 48 h de incubação.

${ }^{3}$ Redução relativa da germinação das sementes.

${ }^{4}$ Redução relativa da emergência de plântulas.

${ }^{5}$ Comprimento de lesão no colmo de plântulas inoculadas por ferimento.

de 51,83\%, sendo esta $>30 x$ superior à incidência por F. verticillioides $(\mathrm{P}=0,0001)$. No entanto, após $96 \mathrm{~h}$ de incubação, todas as sementes apresentavam-se totalmente colonizadas indiferente ao isolado (dados não apresentados). Isolados do complexo Fg também foram os que mostraram maior taxa de crescimento micelial, o que pode ter influenciado na colonização das sementes. A redução na germinação das sementes inoculadas variou de $50 \%$ a $93,48 \%$ (Tabela 1). Fusarium verticillioides reduziu em $69,57 \%$ a germinação, valor inferior $(\mathrm{P}=0,0449)$ à redução de $79,17 \%$ provocada pelos isolados do complexo $\mathrm{Fg}$. A diferença entre $\boldsymbol{F}$. verticillioides e os isolados Fg foi devida principalmente aos isolados $\boldsymbol{F}$. meridionale $(80,98 \%)$, uma vez que não houve evidência de diferença entre isolados $\boldsymbol{F}$. verticillioides e $\boldsymbol{F}$. graminearum s.s. $(75,54 \%)(\mathrm{P}=0,3446)$. A redução na emergência de plântula variou de $50 \%$ a $100 \%$, sendo que a média para isolados $\boldsymbol{F}$. verticillioides $(65,15 \%)$ foi menor do que para os do complexo $\mathrm{Fg}(86,74 \%)$ $(\mathrm{P}=0,0011)$. Não houve $(\mathrm{P}=0,4398)$ diferença entre as espécies do complexo Fg que apresentaram média de $86,66 \%$ e $90,91 \%$ (Tabela 1). MUNKVOLD \& O'MARA (2002), estudando o efeito de fungicidas no controle do tombamento de plântulas de milho por 12 isolados de Fusarium spp., observaram os menores valores de emergência de plântulas provocados por isolados de $\boldsymbol{F}$. graminearum $(31,0-47,6 \%)$, sendo estes aproximadamente $2 \mathrm{x}$ inferiores aos isolados $\boldsymbol{F}$. verticillioides $(88,1-95,2 \%)$ no tratamento testemunha. Da mesma forma, Damicone et al. (1988), em um estudo com isolados de $\boldsymbol{F}$. verticillioides inoculados em grãos de aveia e plantados junto às sementes de milho no campo, observaram de 24 a $46 \%$ de redução na emergência de plântulas. Essa baixa habilidade dessa espécie em afetar o estabelecimento da cultura 
permite o desenvolvimento das plantas e a transmissão do patógeno para a parte aérea, podendo este chegar aos grãos da espiga, uma vez que $\boldsymbol{F}$. verticillioides pode causar infecção sistêmica sem o aparecimento de sintomas externos (WILKE et al., 2007). Todos os isolados foram patogênicos pela inoculação por ferimento em colmos de plântulas de milho de 30 dias de idade. No entanto, a agressividade inferida pelo comprimento das lesões variou entre os isolados individuais ou agrupados pelas espécies $(0,85 \mathrm{~cm}$ a $5,35 \mathrm{~cm}$ ) (Tabela 1). Na literatura, são escassos trabalhos que comparam conjuntamente características de agressividade dessas duas espécies causando podridão em colmo e/ou em espigas, principalmente para $\boldsymbol{F}$. graminearum. JARDINE \& LESLIE (1999), em um estudo de patogenicidade com quatro isolados de $\boldsymbol{F}$. verticillioides, inoculados pelo método do palito em colmo de plantas de dois híbridos de milho, no estádio de pendoamento, observaram que todos os isolados causaram lesões nos colmos, com comprimento variando de 13 a $22 \mathrm{~cm}$.

O comprimento médio geral das lesões provocadas por $\boldsymbol{F}$. verticillioides $(1,04 \mathrm{~cm})$ foi $2,5 \mathrm{x}$ inferior àquele provocado pelos isolados $\mathrm{Fg}$ $(2,63 \mathrm{~cm}) \quad(\mathrm{P}=0,0001)$ (Tabela 1). MIEDANER et al. (2010), em um estudo de campo conduzido na Alemanha, compararam a patogenicidade de isolados de $\boldsymbol{F}$. graminearum com quimiotipo DON ou NIV e $\boldsymbol{F}$. verticillioides, produtor de fumonisina, pela inoculação da planta através dos estigmas sete dias após o florescimento em híbridos suscetíveis e resistentes de milho. Os autores observaram que a média de severidade da podridão da espiga, provocada pelos isolados de $\boldsymbol{F}$. graminearum produtores de DON, foi a mais alta $(62,9 \%)$, seguido dos produtores de NIV $(24,2 \%)$ e, por último, por isolados de $\boldsymbol{F}$. verticillioides $(9,8 \%)$. No presente estudo, diferentemente do estudo da Alemanha, a agressividade inferida pelo comprimento das lesões em colmos de plântulas de 30 dias foi semelhante entre os isolados $\boldsymbol{F}$. graminearum s.s. $(3,23 \mathrm{~cm})$ e $\boldsymbol{F}$. meridionale $(2,33 \mathrm{~cm})(\mathrm{P}=0,4398)$ (Tabela 1), podendo essa inconsistência ser devida a características das espécies do complexo. Pela ordenação das variáveis, foi possível identificar, dentre aquelas analisadas, quais apresentaram maior importância na caracterização dos isolados fúngicos (Tabela 2). Os dois primeiros componentes principais $\left(\mathrm{CP}_{1}=\right.$ redução de emergência e $\mathrm{CP}_{2}=$ redução de germinação) apresentaram autovalores iguais a 2,86 e 0,87 e contribuíram com 57,20\% e 17,39\% na variância total observada em cada componente (eixo), o que, somado, explica 74,5\% da variância entre os isolados (Tabela 2). Esse resultado sugere que, em estudos futuros, as avaliações da germinação de sementes e
Tabela 2 - Análise de componentes principais para variáveis que representam características fisiológicas e patogênicas em um grupo de doze isolados, sendo seis de Fusarium verticillioides e seis de Fusarium graminearum.

\begin{tabular}{lll}
\hline Variável $^{\mathrm{y}}$ & $\mathrm{CP}_{1}{ }^{\mathrm{x}}$ & $\mathrm{CP}_{2}$ \\
\hline Autovalores & 2,86 & 0,87 \\
\% Variância & 57,20 & 17,39 \\
Semente totalmente colonizada após 48 h (\%) & 0,47 & 0,01 \\
Redução da germinação de sementes (\%) & 0,30 & 0,89 \\
Redução de emergência de plântulas (\%) & 0,54 & $-0,05$ \\
Taxa de crescimento micelial (mm/dia) & $0,39^{\mathrm{z}}$ & $-0,28$ \\
Agressividade em colmos (cm) & 0,49 & $-0,34$ \\
\hline
\end{tabular}

${ }^{y}$ Autovalores e variância associados aos componentes.

${ }^{\mathrm{x}}$ Componentes principais.

${ }^{\mathrm{z}}$ Autovetores das variáveis de caracterização dos isolados de Fusarium spp. em que as variáveis redução de emergência de plântulas e redução da germinação de sementes correspondem a $57,2 \%$ e a $17,39 \%$ da variância dos descritores originais dos dois primeiros componentes, respectivamente.

da emergência de plântulas devem ser priorizadas na caracterização de isolados de Fusarium spp. em milho. Ainda, em estudos de tratamento de sementes com fungicidas, em que se visa a avaliar a eficiência de fungicidas protetores na redução/erradicação dessas espécies, devem ter como alvo biológico o complexo Fg, uma vez que Fusarium verticillioides possui uma menor taxa de crescimento micelial, menor eficiência de colonização de sementes, menor redução na emergência de plântulas e menor tamanho de lesão em colmos, quando comparados aos isolados do complexo Fg. Finalmente, as medidas de redução da germinação e redução da emergência são bons indicadores na caracterização, principalmente das duas espécies biológicas, uma vez que não houve diferença entre as espécies filogenéticas do complexo F. graminearum.

\section{CONCLUSÃO}

Fusarium verticillioides e o complexo $\boldsymbol{F}$. graminearum apresentaram padrões distintos quanto à taxa de crescimento micelial e características patogênicas em sementes e plântulas de milho, sendo esses similares entre as espécies do complexo $\boldsymbol{F}$. graminearum, as quais representam maior risco ao estabelecimento da cultura pela maior redução de germinação e emergência de plântulas.

\section{REFERÊNCIAS}

ASTOLFI, P. et al. Molecular survey of trichothecene genotypes of Fusarium graminearum species complex from barley in Southern 
Brazil. International Journal of Food Microbiology, v.148, 197201, 2011.Disponível em: <http://www.sciencedirect.com/science/ article/pii/S0168160511003023>. Acesso em: 15 set. 2012.

ASTOLFI, P. et al. Genetic population structure and trichothecene genotypes of Fusarium graminearum isolated from wheat in southern Brazil. Plant Pathology, v.61, p.289-295, 2012 Disponível em: <http://onlinelibrary.wiley.com/doi/10.1111/ j.1365-3059.2011.02515.x/full>. Acesso em: 15 set. 2012.

CASA, R.T. et al. Fungos associados à semente de milho produzida nas Regiões Sul e Sudeste do Brasil. Fitopatologia Brasileira, v.23, p.370-373, 1998.

DAMICONE, J. et al. Cross-pathogenicity of Fusarium moniliforme isolates from corn and asparagus. Plant disease, v.72, p.774-777, 1988.

DESJARDINS, A.E. Natural product chemistry meets genetics: when is a genotype a chemotype? Journal of agricultural and food chemistry, v.56, p.7587-7592, 2008. Disponível em: <http://www. ncbi.nlm.nih.gov/pubmed/18690691>. Acesso em: 15 maio. 2011.

JARDINE, D.J.; LESLIE, J.F. Aggressiveness to mature maize plants of $\boldsymbol{F}$ usarium strains differing in ability to produce Fumonisin. Plant Disease, v.83, p.690-693, 1999. Disponível em: <http:// apsjournals.apsnet.org/doi/abs/10.1094/PDIS.1999.83.7.690>. Acesso em: 3 nov. 2011.

JURJEVIC, Z. et al. Fusarium species of the Gibberella fujikuroi complex and fumonisin contamination of pearl millet and corn in Georgia, USA. Mycopathologia, v.159, p.401406, 2005.Disponível em: <http://www.ncbi.nlm.nih.gov/ pubmed/15883726>. Acesso: 13 maio. 2011

LESLIE, J. F.; SUMMERELL, B.A. The Fusarium laboratory manual. Ames: Blackwell Publishing, 2006. 388p.

MACHADO, J.C. et al. Uso da restrição hídrica na inoculação de fungos em sementes de milho. Revista Brasileira de Sementes, v.23, p.88-94, 2001.Disponível em: <http://www.abrates.org.br/ revista/artigos/2001/v23n2/artigo12.pdf >. Acesso em: 17 set. 2012.

MIEDANER, T. et al. Aggressiveness and mycotoxin production of eight isolates each of Fusarium graminearum and Fusarium verticillioides for ear rot on susceptible and resistant early maize inbred lines. European Journal of Plant Pathology, v.127, p.113-123, 2010. Disponível em: <http://www.springerlink.com/ index/10.1007/s10658-009-9576-2>. Acesso em: 1 ago. 2010. doi: 10.1007/s10658-009-9576-2.

MUNKVOLD, G.P. Epidemiology of Fusarium diseases and their mycotoxins in maize ears. European Journal of Plant Pathology, v.109, p.705-713, 2003. Disponível em: <http://www.springerlink. com/index/U3HQ4P6074WU04M8.pdf>. Acesso em: 31 dez. 2010.

MUNKVOLD, G.P.; DESJARDINS, A.E. Fumonisins in maize: can we reduce their occurrence? Plant Disease, v.81, p.556565, 1997. Disponível em: <http://apsjournals.apsnet.org/doi/ abs/10.1094/PDIS.1997.81.6.556>. Acesso em: 17 set. 2012.

MUNKVOLD, G.P.; O'MARA, J.K. Laboratory and growth chamber evaluation of fungicidal seed treatments for maize seedling blight caused by Fusarium species. Plant Disease, v. 86, p.143-150, 2002. Disponível em: <http://apsjournals.apsnet.org/ doi/abs/10.1094/PDIS.2002.86.2.143>. Acesso em: 17 set. 2012.

NDOYE, M. et al. Nivalenol and 15-acetyldeoxynivalenol chemotypes of Fusarium graminearum clade species are prevalent on maize throughout China. Journal of Phytopathology, v.160, p.519-524, 2012. Disponível em: <http://onlinelibrary.wiley.com/ doi/10.1111/j.1439-0434.2012.01944>. Acesso em: 15 set. 2012.

NERBASS, F.R. et al. Sanidade de sementes de milho comercializadas na safra agrícola de 2006/07 em Santa Catarina e no Rio Grande do Sul. Revista de Ciências Agroveterinárias, v.7, p.30-36, 2008. Disponível em: <http://rca.cav.udesc.br/ rca_2008_1/nerbass_et_al.pdf $>$. Acesso em: 15 set. 2012.

PILLAR, V.D. The bootstrapped ordination re-examined. Journal of Vegetation Science, v.10, p.895-902, 1999. Disponível em: <http://onlinelibrary.wiley.com/doi/10.2307/3237314/pdf >. Acesso em: 15 set. 2012

PILLAR, V.D. Multiv: software para análise multivariada, testes de aleatorização e auto-reamostragem "bootstrap". Porto Alegre: Departamento de Ecologia, Universidade Federal do Rio Grande do Sul, 2001. Disponível em: 〈http://ecoqua.ecologia.ufrgs.br〉. Acesso em: 10 jun. 2012.

RAS. Regras para análise de sementes/Ministério da Agricultura, Pecuária e Abastecimento. Secretaria de Defesa Agropecuária. Brasília: Mapa/ACS, 2009.399p.

RIBEIRO, N.A. et al. Incidência de podridões do colmo, grãos ardidos e produtividade de grãos de genótipos de milho em diferentes sistemas de manejo. Ciência Rural, v.35, p.10031009, 2005. Disponível em: <http://dx.doi.org/10.1590/S010384782005000500004>.Acesso em: 30 jul. 2012.

SARVER, B.A. et al. Novel Fusarium head blight pathogens from Nepal and Louisiana revealed by multilocus genealogical concordance. Fungal Genetics and Biology, v.48, p.1096-1107, 2011. Disponível em: <http://www.sciencedirect.com/science/ article/pii/S1087184511001721>. Acesso em: 15 set. 2012

SILVA, C.N. Identificação molecular de espécies de Fusarium e genes preditivos de micotoxinas associados aos grãos de milho e trigo no centro-sul do Brasil. 2011. 93f. Dissertação (Mestrado em Agronomia) - Curso de Pós-graduação em Agronomia, Universidade Estadual de Maringá, PR.

SPOLTI, P. et al. Phenotypic and pathogenic traits of two species of the Fusarium graminearum complex possessing either 15-ADON or NIV genotype. European Journal of Plant Pathology, v.133, p.621-629, 2012. Disponível em: <http://www.springerlink.com/ index/10.1007/s10658-012-9940-5>. Acesso em: 4 set. 2012.

STEWART, D.W. et al. A mathematical simulation of growth of Fusarium in maize ears after artificial inoculation. Phytopathology, v.92, p.534-541, 2002. Disponível em: <http://www.ncbi.nlm.nih. gov/pubmed/18943028>. Acesso em: 12 set. 2012.

STUMPF, R. et al. Fusarium species and fumonisins associated with maize kernels produced in Rio Grande do Sul State for the 2008/09 and 2009/10 growing seasons. Brazilian Journal of Microbiology, (no prelo), 2013.

TORRES, P.S. et al. Properties of a randomization test for multifactor comparisons of groups. Journal of Statistical Computation and Simulation, v.80, p.1131-1150, 2010. Disponível em: <http:// www.tandfonline.com/doi/pdf/10.1080/00949650902984430>. Acesso em: 17 set. 2012. doi: 10.1080/00949650902984430.

WILKE, A.L. et al. Seed transmission of Fusarium verticillioides in maize plants grown under three different temperature regimes. Plant Disease, v.91, p.1109-1115, 2007. Disponível em: <http:// apsjournals.apsnet.org/doi/abs/10.1094/PDIS-91-9-1109>. Acesso em: 11 set. 2012. doi: 10.1094/PDIS-91-9-1109. 